\title{
The co-presence of clarity and ambiguity in strategic corporate communication
} an exploratory study

Gulbrandsen, lb Tunby

Published in:

International Journal of Strategic Communication

DOI:

10.1080/1553118X.2019.1575222

Publication date:

2019

Document Version

Peer reviewed version

Citation for published version (APA):

Gulbrandsen, I. T. (2019). The co-presence of clarity and ambiguity in strategic corporate communication: an exploratory study. International Journal of Strategic Communication, 13(2), 95-109.

https://doi.org/10.1080/1553118X.2019.1575222

\section{General rights}

Copyright and moral rights for the publications made accessible in the public portal are retained by the authors and/or other copyright owners and it is a condition of accessing publications that users recognise and abide by the legal requirements associated with these rights.

- Users may download and print one copy of any publication from the public portal for the purpose of private study or research.

- You may not further distribute the material or use it for any profit-making activity or commercial gain.

- You may freely distribute the URL identifying the publication in the public portal.

\section{Take down policy}

If you believe that this document breaches copyright please contact rucforsk@kb.dk providing details, and we will remove access to the work immediately and investigate your claim. 


\title{
The co-presence of clarity and ambiguity in strategic corporate communication - an exploratory study
}

\author{
Ib T. Gulbrandsen, Roskilde University
}

\begin{abstract}
The purpose of this article is to examine the co-presence of clarity and ambiguity in the formulation, interpretation and implementation of corporate communication strategies. Following a growing scholarly interest in how ambiguity can be seen as a productive strategic resource in strategy work, this article focuses on the interdependency of clarity and ambiguity in corporate communication strategies. Through an exploratory study, using interpretive discourse analysis of interviews with employees at a corporate communication department, the present article analyses how the employees perceived the writing, reading and enactment of their organization's new corporate communication strategy. The analysis reveals that the employees sometimes use shared understandings to produce ambiguity in relation to engagement and responsibility, and how they use ambiguity to create a shared understanding on objectives and practices. Though this copresence might cause the members to feel a lack of ownership, it does not impede the department's ability to execute strategy-work.
\end{abstract}

\section{Citation:}

Gulbrandsen, I. T. (2019). The co-presence of clarity and ambiguity in strategic corporate communication: an exploratory study. International Journal of Strategic Communication, 13(2), 95109. https://doi.org/10.1080/1553118X.2019.1575222 


\section{Introduction}

Currently, the majority of strategic corporate communication (SCC) literature defines its domain as one in which clarity is present and ambiguity is absent. That is, a field where being strategic is equal to the organization having well-defined, planned objectives for and well-aligned, harmonized implementation of its communicative efforts designed to create and/or maintain favourable relations with its stakeholders (see e.g. Jackson, 1987; Sinha \& Bhatia, 2016; van Riel \& Fombrun, 2007). The underlying logic is that clarity and consistency are prerequisites for trust and credibility (which the organization must seek in order to succeed), hence the organization must avoid any gaps and discrepancies in their planning and execution of communication (Balmer \& Greyser, 2003; Ormino, 2007; Seiffert, Bentele \& Mende, 2011).

But, notwithstanding the importance and appropriateness of focusing on clarity in relation to SCC, it cannot stand alone. Within the broader field of organization studies and strategic management, the objection to this sole focus on consistency and (often inadvertently) rationality is longstanding and well known (see e.g. Cohen, March, \& Olsen, 1972; Lindblom, 1959; Mintzberg, 1994; Weick, 1979). As these scholars, and others following them, have pointed out, not only can organizations in general act in ambiguous ways, but so can their strategies. For instance, in aiming to reorient the locus of strategy research to the micro-dynamics of strategy-making, scholars associated with the strategy-as-practice (SAP) field (see e.g. Whittington 2006, Jarzabkowski, Balogun \& Seidl, 2007), have argued that strategy needs to be understood from "an interpretive approach in which the world cannot be understood independently of the social actors and processes that produce it" (Kaplan, 2007, p. 988). That is, we need to give attention to the multiple, divers, and divergent actors that influence the organization's strategy and ability to strategize (Plesner \& Gulbrandsen, 2015).

A similar argument has been made within the field of organisation communication, where for instance Eisenberg, in a critical response to the "optimal model" of communication (which equates strategy with clarity), state that "a communicator's goals [cannot be] assumed to be unitary or even consistent; rather, individuals have multiple, often conflicting goals which they orient toward in an effort to satisfy rather than to maximize attainment of any one goal in particular." (Eisenberg, 1984, p. 231). The point here being, that due to the polyphony of organizational life, where multiple and contrasting voices exist simultaneously and autonomously (Christensen, Morsing \& Thyssen, 2015; Gulbrandsen \& Just, 2016a, Hazen, 1993; Humphreys \& Brown, 2002), 
clarity is not always attainable, nor necessarily desirable, in the formulation and implementation of strategy.

Yet, despite these earlier and contemporary insights, the SCC field is still predominantly focused on how (and why) organizations need to focus on avoiding ambiguity and uncertainty if it is to succeed. This emphasis could, as Christensen et al. (2015) argue, beyond theoretical conservatism, be a result of the growing societal intolerance for any discrepancy in the communication from and about organizations, creating a situation where organizations are expected to align their behaviours as well as their messages in order to accurately and unambiguously reflect the underlying organizational reality. But as Christensen et al. (2015) also point out, by insisting on clarity as the most important goal of SCC, we are also rejecting the idea that communicative processes, including those we deem strategic, can be arbitrary, conventional and polysemic.

The purpose of this article is therefore to examine the role of ambiguity in relation to SCC, in particular the co-presence of clarity and ambiguity in the formulation, interpretation and implementation of corporate communication strategies. It will do so through an exploratory study of strategy-work at a corporate communication department. The research aims to contribute not only to the theoretical development of SCC, but also its practice: First, by arguing how the failure to recognize the co-presence of clarity and ambiguity prevents scholars from understanding the actual workings of SCC, and instead forces them to focus on what one could call the mirage of clarity. And, following, how it inhibits practitioners and managers from fully realising the potential of SCC processes, and as such waste valuable organizational resources due to mismanagement. The study does not seek to argue this at the expense of clarity being an important trait of SCC, but by arguing the there is also a need to focus on and allow for equivocality in understanding and practicing SCC.

The structure of the article, is as follows: First, the SCC field's focus on clarity will be discussed and juxtaposed to theories and studies arguing for the unavoidable and potentially productive presence of ambiguity in strategy-work. Second, the analytical and methodological approach will be detailed. And, third, the study's findings will be presented, followed by a discussion of its potential implications, with the aim of contributing to the field of SCC by giving attention to how the strategy or 'strategicness' of corporate communication can have varied expressions as it is affected by different organisational actors trying to make sense of the strategy. 


\section{Clarity vs. ambiguity}

In most literature on corporate communication, the domain is conceptualized as the overall organizational communication activity aimed at achieving planned and deliberate communication objectives in order to create a favourable relationship with the organization's stakeholders (Jackson, 1987), often with an emphasis on it being a managerial tool that aids the alignment of internal and external communications effectively and efficiently (van Riel \& Fombrun, 2007; Steyn, 2003). From an external point of view, SCC is concerned with how to match different communication channels with different stakeholder groups (see e.g. Balmer \& Greyser, 2003), how to design feedback mechanisms to ensure input from the stakeholders in the construction of suitable and effective messages (see e.g. Argenti, 2007), and how to ensure the organization serves as a primary among many sources to which the stakeholders are exposed in their multiple variable image formation process (Cornelissen, 2000).

Internally, on the other hand, SCC is understood as the managerial process of communicating an organization as a unique, identifiable and trustworthy entity (Christensen \& Cornelissen, 2011) - the all-encompassing structure for how to manage the total company message. As van Riel (2003, p. 54) puts it, SCC is

The orchestration of all the instruments in the field of organizational identity (communication, symbols and behavior of organizational members) in such an attractive and realistic manner as to create or maintain a positive reputation for groups with which the organization has an interdependent relationship.

The point of this "orchestration" is to avoid ambiguity by managing communication as an integrated and consistent whole (Christensen, Morsing \& Cheney, 2008). That is, ensuring internal clarity on strategy-objectives; well-defined links between the communication strategy and the overall organizational mission, vision and values; precision in the coordination of organizational activities; and meticulousness in the integration of different communicative efforts (see e.g. Argenti, 2007; Goodman, 2006; van Riel \& Fombrun, 2007; Seiffert et al., 2011). Any discrepancy and inconsistency should be avoided, whether in development, understanding or execution of the strategy, as this will result in the organization being less able to build and/or maintain a favourable image, and, in worst-case, lose public trust (Seiffert et al., 2011).

As noted in the introduction, this focus on clarity over ambiguity is understandable considering the current pressure and scrutiny organizations experience from stakeholders. A 
pressure to be accurate and scrutiny of behaviour fuelled by the rise of new media - providing stakeholders with new information sources - and recent corporate scandals, both financial and ecological, prompting stakeholders to pay more attention (Christensen et al., 2015). But this focus is also obscuring the 'organizational reality' of SCC.

Multiple scholars within organisational communication and strategic communication have argued for a departure from this sole focus on consistency and (often inadvertently) rationality as defining features of organisational life, by noting that “...organizations are not discursively monolithic, but pluralistic and polyphonic, involving multiple dialogical practices that occur simultaneously and sequentially" (Humphreys \& Brown, 2002, p. 422; see also Ashcraft, Kuhn \& Cooren, 2009; Fairhurst \& Putnam, 2004). This means that even though organizational pluralism and polyphony can be supressed by guidelines and directives, it is beyond reach for any sender fully to control the interpretation (and subsequent action) and spread of a message (Gulbrandsen \& Just, 2016b; Hallahan, Holtzhausen, van Ruler, Verčič, \& Sriramesh, 2007). Rather, both internally and externally, an organization's communicative efforts always experience alteration by some and rejection by others (Christensen et al., 2015; King, 2009). As such, a communicator's goals (be it organization, management, employee or stakeholder) should not be assumed to be inherently clear or even consistent when formulated or implemented. Rather, communicators will often have "multiple, often conflicting goals which they orient toward in an effort to satisfy rather than to maximize attainment of any one goal in particular." (Eisenberg, 1984, p. 231). What this means for the notion of clarity, is that it should not be seen as an attribute of any communicative process or act, but rather as a relational variable, which arises from the changing functional roles of the source, message, and receiver involved in the process and/or act (Eisenberg, 1984, p. 231; Emirbayer, 1997). Clarity will therefore only be present if and when "a source has narrowed the possible interpretations of a message and succeeded in achieving a correspondence between his or her intentions and the interpretation of the receiver" (Eisenberg, 1984, p. 232). In other words, only under certain circumstances will there exist clarity - in most instances there will be ambiguity.

Criticism of the prevalent emphasis on clarity and rationality is also present within the field of strategic management, where it has gained new prominence with the rise of the strategy-aspractice (SAP) field (see e.g. Vaara \& Whittington, 2012; Whittle \& Mueller, 2010). That is, theories and studies arguing for a reorientation of strategy research "towards the micro" (Johnson et al., 2007: 14) by focusing on the "living beings whose emotions, motivation and actions shape strategy" (Jarzabkowski and Spee, 2009: 70). Drawing on theory of practice, sense-making and 
discourse the SAP literature suggests that we need to see strategy as something people do (Jarzabkowski, 2004: 529), and that the goal of strategy research should be to "get much closer to the detailed activities that go on inside organizational processes" (Johnson, Langley, Melin, \& Whittington, 2007: 13) instead of solely providing prescriptive ideas and ideals of how strategy works. What this strand of research has reinvigorated is the acknowledgement of the fallacy of both clarity and rationality as guiding principles in organisational life by reintroducing concepts such as Simon's (1947) bounded rationality, Lindblom's (1959) muddling through, Cohen, March and Olsen's (1972) garbage can decisions, and Mintzberg's (1994) notion of emergent strategy. Within SAP, as well as the wider field of strategic management, it is thus argued that strategy plans and strategy discourses often are vague, highly developmental and ambiguous as a result of trying to accommodate the perspectives of multiple stakeholders, meaning that full clarity is absent due to the polysemic reality of organizational life (e.g. Denis, Langley \& Lozeau, 1991; Jarzabkowski \& Fenton, 2006; Vaara et al., 2010; Tracy \& Ashcraft, 2001).

One could of course argue that for SCC the goal is to counter this polysemic reality and ensure clarity and stability in strategy-work, but many scholars would argue that such an attempt will not only fail, but could even be counterproductive to achieving the strategic goals. Eisenberg, for instance, point to how ambiguity in a manager's communication with subordinates, "may improve performance by allowing him or her the freedom and creativity to excel" (Goodall, Wilson, \& Waagen, 1986, p. 77, in Eisenberg, 2006, p. 65). Denis, Dompierre, Langley and Rouleau (2011) point to how ambiguity can be utilized in situations where agreement on strategy appears elusive or unattainable, an argument similar to that of Spee \& Jarzabkowski (2017), who point to how ambiguity allow for divergent meanings and perceptions about strategy to coexists, without thwarting organizational members' ability to act. As such, ambiguity is seen as a productive feature of strategy-work. It can be exploited by managers to ensure employees' engagement in strategy work under the impression that their interests are met (Sillince, Jarzabkowski \&Shaw, 2012), including disguise strategy-work aimed at increasing control over employees (Davenport \& Leitch, 2005). Ambiguity can also provide organisational members wide scope for interpretation of responsibility in relation to strategy-work, allowing them to shift blame dependent on the success of the strategy (Sillince \& Mueller, 2007). And it can be used to prevent both the organisation as a whole, and its members, to lose face should a strategic initiative, action or communication need to be fully retracted (Eisenberg, 2006). The notion of obtaining a "shared meaning" as the sole benchmark of effective strategy-work, is hence abandoned in favour of "an approach that 
emphasizes the achievement of sufficient cognitive alignment to facilitate coordinated action." (Eisenberg, 2006, p. 25). Compared to how ambiguity is perceived in the dominant SCC literature, these scholars rather see ambiguity as a productive feature of strategy-work. Clarity, it is argued, could, instead of ensuring fulfilment of strategic goals, actually endanger the fulfilment by putting constraints on decision- or behavioural options. As such, clarity and alignment are not seen as determining features of, or even necessary for, the success of formulating, understanding and implementing strategy.

There are some scholars, however, that warn against this portrayal of ambiguity as solely productive. Not by arguing that it is unproductive, but that it can also thwart or slow down action. Abdallah and Langley (2014), for instance, call for attention to the double-edge nature of ambiguity (see also Jarzabkowski, Sillince, \& Shaw, 2010): it allows for participation in and implementation of strategy-work, but can also, over time, produce misalignment and conflict, potentially blocking substantial strategic action. That is, rather than an either/or approach to ambiguity, we need to focus our attention to when it is productive, and when it is less so.

But, as the above review shows, such a nuanced perspective on the presence and duality of ambiguity in corporate communication strategy-work has been given only little attention. The purpose of this article is hence, through a study of strategy-work at a corporate communication department, to address this gap in the literature and examine the role of ambiguity in the formulation, understanding and implementation of corporate communication strategies.

\section{The writing, reading and enactment of SCC}

As this is a fairly uncharted territory within the SCC field, the present study is exploratory, meaning a study "that investigates distinct phenomena characterized by a lack of detailed preliminary research, $[\ldots]$ exploring a relatively new field of scientific investigation in which the research questions have either not been clearly identified and formulated or the data required for a hypothetical formulation have not yet been obtained." (Streb, 2010, p. 373). Hence, for guidance, I have looked to organizational discourse studies, in particular in terms of how strategy and strategizing can be seen as becoming existent through the organisational members' use of language (Sajasalo, Auvinen, Takala, Järvenpää, \& Sintonen, 2015). Specifically, this exploratory study has found guidance in Abdallah and Langley's (2014) operationalisation of strategy-work, dividing it into three separate stages or processes: the writing, reading and enactment of strategy. But contrary 
to their employment of this framework, the present analysis does not, in terms of writing, look into the concrete strategy text, but instead how the department members describe the actual process of formulating the text - the writing process. In terms of the reading and enactment, however, the present analysis is parallel to theirs. The reading of strategy is understood as the members' appropriation of the strategy discourse present in the written strategy text. With reference to de Certeau (1988), Abdallah and Langley argue that beyond the actual strategy text, it is vital to consider how members of an organization "creatively 'consume' the text" (2014, p. 238), meaning what they make of it and how they connect to it. Finally, the enactment of strategy is understood as the concrete consequences of the members' appropriation of the strategy discourse, meaning what strategic action(s) the members perceive it affords.

As a consequence of this chosen framework, the research design employed is interpretive discourse analysis, where discourse is understood as a "particularly ordered, integrated way of reasoning" (Alvesson \& Kärreman, 2000, p. 1125), which offers structures for organizational action and practice by "stabilizing meaning" (p. 1137) at given points in time. The analytical approach is textual interpretation in which central themes and thematic constructions and interconnections are identified and patterns in the data elaborated (Heracleous, 2006). The purpose is to identify streams of meanings exhibited in texts in order to understand and depict how discourses shape and are shaped by social practices (Grant, Keenoy, \& Oswick, 1998; Heracleous, 2006).

\section{Case, data and analysis}

The present study was conducted in the corporate communication department of one of Europe's largest media and publishing houses with over 6.000 employees and 1,5 billion Euro in revenue. The organization operates globally, but most of its activities are placed in Europe. As with many other publishing houses, the organization is, due to technological advances and economic downturn, facing a drop in book sales, decline in subscribers to print magazines and an increasingly competitive and changing television market. In trying to cope with the situation, the organization as a whole, and its corporate communication department in particular, set out to formulate and implement a new strategy. The process at the department began in early 2013, but did not fully evolve until after a new Vice President of Corporate Communications was hired in early 2014. As such, the case can be described as an "extreme case" (Seawright \& Gerring, 2008; Yin, 2003), meaning most likely to provide insight into the organizational 'strategy-reality', where 
organizational members' use of language in the writing, reading and enactment of strategy can be observed as they are faced with not only a new strategy, but also new leadership. At the time of the study (second and third quarter, 2014) the department had 12 full-time employees.

Having gained access to the department, and following the participation in four department meetings, and a background interview with the Vice President, all 12 employees were interviewed between June and September, 2014. The interviewees had between 2,5 months and 20 years of tenure. All interviews were conducted in a meeting room on the same floor as, but isolated from, the offices of the corporate communication department at the organization's headquarters. The interviews lasted 40 minutes to one hour and were all digitally recorded. Following, the interviews were transcribed by a research assistant based on a sample transcription by the author and a transcription guide. The interviews were conducted following a semi-structured design (Denzin \& Lincoln, 2000), and the themes structuring the conversation were related to the work history and primary discipline, understanding of the process through which the corporate communication strategy was formulated, as well as the content and implementation of the strategy. The semistructured design was chosen in order to ensure that the interviews played out as structured conversations, allowing a reflexive-interpretive approach (Alvesson, 1996) to understanding the subjective world of the interviewees - their beliefs, attitudes and perceptions (Silverman, 2001).

In order to gain access, the organization required that neither the name of the organization, nor the names of the interviewed members be used in any publication of the study. As this author did not find that this hindered the investigation, nor the dissemination of the study in that the names themselves are not of significant relevance to the study's findings and scientific contribution, the author accepted this. As such, the interviewees have been given generic names that only reflect the gender of the interviewee. For a list of interviewees, see table 1. 
Table 1: Interviewees

\begin{tabular}{|l|l|l|}
\hline Name & Primary discipline & Tenure \\
\hline VP (Vice President) & Management and public affairs & 1 year \\
\hline Allan & Internal communication & 2.5 years \\
\hline Bill & Public relations & 6 years \\
\hline Catherine & Online communication & 5 years \\
\hline Donna & Public relations & 12 years \\
\hline Ellen & Internal communication & 20 years \\
\hline Fran & Public relations & 5 months \\
\hline Gloria & Internal communication & 10 years \\
\hline Helen & Brand management & 11 years \\
\hline Isabel & Online communication & 3 months \\
\hline Jill & Public relations & 1 year \\
\hline Karen & Internal communication & 3 years \\
\hline
\end{tabular}

The data analysis was organised in two phases. First, each transcript was read thoroughly by the author and then compared, enabling the identification of central themes based on the exhibited similarities and differences. Second, focusing particularly on the meanings the interviewees associated with the writing, reading and enactment of the corporate communication strategy, interview excerpts with most relevance from the otherwise extensive transcriptions were identified and analysed, allowing a deeper interpretation of the data. As such, the first phase of data analysis was a qualitative theme analysis, whilst the latter was a qualitative content analysis (Sajasalo et al., 2015; see also Stake, 2010). The analysis was centred around three research questions derived from Abdallah and Langley's (2014) operationalisation of strategy-work: 1) how do the department members perceive the process of writing the corporate communication strategy, 2) how do they read, and hence understand, the written strategy, and finally, 3) how do they describe the process of implementing the strategy, meaning the enactment of it. 


\section{The co-presence of clarity and ambiguity in SCC}

In the following, main findings from the analysis are presented. The presentation is structured according to the above-mentioned research questions, focusing first on the writing of strategy, then the reading of it, and finally, the enactment.

\section{The writing of strategy: why are we doing this, and who is doing it?}

One of the main purposes of writing a corporate communication strategy, as argued in the SCC literature, is to operationalise the organisation's overall mission, vision and values into actionable communication activities. But during the interviews with the employees in the department, this does not seem to be the case. Though they all, sometimes verbatim, as if reading from a text book, describe how the purpose of a strategy is to enable the department in formulating and achieving a set of objectives based on the organization's vision and values, none of them describe their own strategy as doing so. If anything, they reject the importance and relevance of the organisation's overall mission, vision and values. Allan states: "When it comes to vision and values... I often find that to be rather loose. I find it difficult to incorporate them in the concrete work. [...] They don't matter to me". Catherine concurs that they do not matter, pointing to how the organization could just as well have had other values she would agree with just as much, and even saying that "they are not part of the strategy. They are never mentioned". Others go even further and describe the corporate mission, vision and values as "clichés" (Isabel) and "corporate bullshit" (Gloria). As such, the department does have a "shared meaning", deemed vital by many SCC scholars (see e.g. Jackson, 1987; van Riel \& Fombrun, 2007), but a bit paradoxically, the shared meaning relates to the uselessness of one of the cornerstones of SCC.

On a departmental level, two contracting clarities are hence present: when asked about the abstract purpose of SCC, it is deemed important to connect the corporate communication strategy to an organisation's mission, vision and values; when asked about the concrete strategy-work of the department, they are deemed unimportant and unproductive. They agree that corporate visions and values are cornerstones of SCC, but they do not find that corporate visions and values serve any purpose in their own SCC writing process. That they agree on the first, merely points to a stabilization of certain patterns of thought over time (Eisenberg, 2006, p. 184), in this case probably caused by similar educational and professional backgrounds. But that they agree on the latter, which fully contradicts the first, points to that the department as a whole has an ambiguous relationship to 
the strategy text. The paradoxical combination of the take-for-grantedness of the abstract purpose of writing a corporate communication strategy, with the agreed-upon uselessness of visons and values in strategy-work, suggests that the status of the text, meaning what purpose it serves and which implications it has, might be less clear for the department. This potentially unclear role of the text is also expressed by the VP herself: "The most important for me is not that we spend time on the strategy or the process, but that we execute.". In other words, she does not assign much meaning or importance to the actual writing processes, or the written document, instead favouring action. By doing so, the VP, by almost admitting that there might not be an answer as to why they are writing the strategy, gives the text itself a fairly ambiguous role in relation to the department's strategywork. Because what is the purpose of the corporate communication strategy if not to operationalise the organisation's overall mission, vision and values into actionable communication activities?

This ambiguous relationship to the strategy text and formulation of it becomes further visible when the employees are asked to describe the concrete process of writing it: they have very different versions of how it played out. Allan, for instance, describes the process as involving several seminars and workshops in which "we had lots of post-its and posters and group work where we offered different thoughts and ideas in relation to different stakeholder groups". This “dialogization discourse" (Mantere \& Vaara, 2010), describing the strategy process as involving dialectics between top-down and bottom-up processes, is also employed by Jill, David and Ellen, saying that they were all part of the process. Ellen in particular points out that the VP "was really good at involving us all", by "sharing information along the way and giving us all the opportunity to provide ideas and input". Bill on the other hand talks of a very different process:

I was first introduced to the strategy during a morning meeting. At that meeting I was also told that the board of directors had already approved it. So it was done, without the involvement of the department. [...] At the meeting we had 30 minutes to give feedback. But the feedback was pointless, since the strategy was done.

Compared to the four employees mentioned above, Bill describes the process as top-down, similar to what Mantere and Vaara (2010) call a "mystification discourse“, with no employee involvement, a version similar to that of Gloria. "I played no role" she says, and goes on to describe how the strategy was presented to the employees as "this is how we will be doing things from now on". Though this discrepancy could be interpreted as mere divergent experiences, Sillince and Mueller (2007) point to how organisational members often will employ ambiguity to shift or assign 
responsibility in order to safe guard themselves against the possible failure of the strategy. Seeing how the interviews were conducted after the strategy had been written, read and enacted, Bill and Gloria's way of describing their experience, could hence point to the need to not take responsibility for it.

This observation is further strengthened by the fact that there is a third version of the writing process expressed in the interviews. Catherine and Helen describe the process of writing as one in which two employees, together with the VP, wrote the strategy. Catherine says:

It is very clear who wrote the strategy. If you look at what it focuses on. Somebody with expertise in branding. And the of course [the VP] and her focus on public relations. And one who works with PR and external communication. It reflects this.

Helen confirms this version, and goes on to explain how they tried to involve the department, but describes this as having been difficult. Both Donna and the VP corroborate this, where the latter says:

It has been a long process, also longer than I perhaps thought was necessary. When I started I wrote a short strategy. Then I involved two employees [mentions their names], who with me wrote more, and we also discussed it at our department meeting.

Across the department, there are thus three different versions of the same process, including three different ways to describe the role of the employee in the process of writing. This is notable seeing how the department is fairly small, and most of them sit in a large shared office space. One would assume that this would foster an environment where a more coherent experience would develop. But, as mentioned above, the lack of coherence in their expressed experience might not reflect the actual process, but rather how in different ways, they either take or reject ownership and responsibility for the strategy. In connection to this, it is worth pointing out the discrepancy between the VP's version, and that of the first four employees. She does not describe it as collaborative, pointing to the potential use of ambiguous language in the presentation of and invitation to the writing process. Some interpreted it as an invitation to participate, others did not, leaving the answer as to whom wrote the strategy open to interpretation.

In sum, the contradicting shared clarities on the departmental level, combined with contradicting ways of retelling the process of writing the text, point to an ambiguous formulation 
process, where the status of the text seems to be unclear, including who is part of it, who is responsible for it and why it is being written. In the analysis of the reading of strategy, this observation is further strengthened.

\section{The reading of strategy: what difference does it make?}

On the question of whether or not the interviewees had read the strategy, they all respond yes. Most had read it in connection to the department meeting mentioned by Bill, where the strategy was presented, though some had read it previous to or following the meeting. When asked if they had a copy of the strategy text, only the VP and Helen had copies. In relation to the content of the strategy, the analysis show that there is overwhelming clarity in regards to the goals and objectives of the strategy: focusing on business to consumer (B2C) communication, and public affairs. Several explain the first as a need to be relevant to consumers and the public, which the organization, they argue, currently is to a very little extent. Pointing to how an awareness and image analysis conducted as part of the writing process showed that a very small number of consumers knew much about the organization (compared to its subsidiaries), the interviewees, such as Fran and Donna, say that this needs to change since a lack of awareness easily translates into difficulties in building trust and credibility (an argument parallel to texts on SCC, see e.g. Balmer \& Greyser, 2003; Ormino, 2007; Seiffert et al., 2011).

In terms of the second objective, focusing on public affairs, a similar clarity on the reasoning of this strategic choice is apparent: the need to be visible to, and connected with the political system since their organization operates in an industry that is regulated. But contrary to the first, the focus on public relations is not explained as being based on analysis or theoretical insight, but rather as a consequence of the hiring, interest and competencies of the VP. As Catherine says:

I actually think it is a bit coincidental in that it's something [the VP] has in her bag. If another person was hired instead of her who was an expert on CSR, well then CSR had probably been the main focus of the strategy. It would have said CSR, CSR, CSR.

In other words, there is a shared meaning on the strategic objective of focusing on public affairs, but contrary to the first objective, this one explained as a direct result of the VP's presence, not analyses, nor strategic necessity. The VP indirectly confirms this by saying: 
... [name of organization] identified, a couple of years back, the organization's primary and secondary stakeholders, and it says, amongst other things, that politicians are primary. But I would have chosen them as primary even if a piece of paper hadn't told me so. Focusing on them is kind of stating the obvious.

Meaning, though she says "a piece of paper" told her to focus on politicians, by also saying that she would have made the choice regardless, she indirectly points to this being an objective that (would have) derived from her anyways, and hence confirms that the objective is not based on analysis, but gut.

This shared understanding, or what Spee and Jarzabkowski (2017) would call "joint account", of the objectives is interesting when considering the ambiguous role the department assigns the text during the writing of it. Despite dismissing the purpose of the strategy as one in which the department operationalises the organisation's mission, vision and values, as well as pointing to how some of the objectives derive from the hiring of the VP (and not the organisation's overall goals), the department is not impeded in creating a collective direction for action.

One possible explanation for this could be that the text is seen as descriptive, rather than prescriptive. That is, the text is understood more as a retrospective sensemaking (Weick, 1979) of what they have always done, rather than as prospective visons (Gioia \& Mehra, 1996) for what they should do. Donna, for instance, explains that even though they have written "what we call a new communication strategy. It really isn't. I would call it an adjusted communication strategy". Karen, Ellen and Helen express the same reading of the strategy, with the latter saying that:

Well, the strategy we are working with now was created in 2003. It has been adjusted, for instance with the focus on PA [public affairs], but it is the same. [...] I don't consider it a new strategy. I mean, now we are just working in new ways in the department. [...] It's a revitalization of the existing.

But some of the employees disagree with this. Catherine for instance reads the strategy as creating real change. She points to how B2C and public affairs are areas "we have never focused on before. I have been here for five years, and the previous boss did not". Jill makes a similar reading of the strategy, arguing that it brings about a big change: "Normally you think that oh, now there's gonna be a new strategy, and then it ends up being the same. But I experienced a significant change this time, for better and worse." As with the writing of the strategy, what becomes clear is that the status of the strategy text is ambiguous. In this case in relation to the question of what difference the 
strategy makes. Some argue no difference, whilst others argue allot, pointing to not only dissimilar readings of the strategy text, but also divergent readings of the previous strategy. But, importantly, this does not hinder clarity on the objectives of the strategy. Rather, the clarity, the shared meaning, seems to be present because of the unclear relationship between the text and the department's concrete strategy-work. A point the following analysis of the enactment of strategy will elaborate on.

\section{The enactment of strategy: which strategy?}

Through the interviews it becomes evident that there is absolute clarity on the work practices at the department, but how they are connected to the strategy is rather ambiguous. All the interviewees describe how they meet every morning for what several call "Newsroom meetings", lasting from 10 to 30 minutes. The term "Newsroom meetings" is not coincidental according to Catherine, since they "get together every day, exactly as if we were a newspaper, and talk about what is happening in the world. Who is talking about us? How should we engage with this?". Fran expands on this by explaining how they "look at press clippings and the calendar, and then decide what we should work on today", decisions that, according to Allan, they collaboratively make during the meeting. Jill seconds this, and adds that if there "is something big going on, we will hold a separate meeting later that day. Perhaps only with those who will be directly involved," pointing to how there is a clear agreement that the meetings should be short, and that longer deliberations should take place elsewhere.

Most of the interviewees explicitly call this practice new and attribute it to the strategy. But when asked where in the strategy text this particular way of enactment is described, they all answer that it was not described, but rather "something new that [the vice president] has created" (Allan). That is, their work practices are indeed connected to a strategy, but not the written strategy. Rather, strategy is now equated with concrete work, and not plans or documents, echoing the definition of strategy as found in the SAP literature, but not the SCC literature. None of the interviewees, including the VP, are actually able to make any direct connection between the objectives of the strategy and the enactment. The orchestration that the SCC calls for (e.g. van Riel, 2003), is hence not found in the strategy text, but is a combination of the concrete daily needs of the department and the VPs preferences. 
Another example of this, is when many of the interviewees describe how they now, following the strategy, are all placed in a big open office structure. Compared to previously, this is a significant change, that, as Gloria explains it, “[n]ot everybody was happy [with] at first.” As with the "newsroom meetings", also this change is presented as a consequence of the strategy, aimed at breaking down the barriers between the different disciplines in the department. But, again, no one can point to where in the strategy text the need to break down barriers is addressed, or how this relates to the overall objectives of the strategy. As such, the interviewees explain how the concrete enactment of the strategy involved significant changes, but they cannot directly relate the changes to the objectives stated in the strategy text.

In answers to questions about the usefulness and importance of the actual strategy document in their strategy enactment, several of the interviewees voice that the strategy is the VP's; she talks about it all the time, but they never use it. Catherine, for instance, complains that the strategy is too long: "Nobody sits there and reads twenty, thirty pages. At least not more than once". Whilst Fran says "Well, when I do my work, I never think about creating awareness [B2C communication] and public relations. I just want to write a good story. I don't think about strategy that much”. A sentiment that is echoed by Isabel, when she says

the strategy is not so relevant for me [...] I don't really use it. When working with social media for instance, having a written strategy seldom helps. Not a written one. I make my own strategies, or action plans,

Not only are the members of the department unable to connect their work practices to the written strategy, some of them even reject the strategy as having any relevance for their work. Rather, they decouple the strategy and the strategy-work, not seeing the former as relevant for the latter, though, similar to observations made by Spee and Jarzabkowski (2017)), without letting this decoupling hinder strategic action. In analysing the interviewees' descriptions of their strategy enactment, one is almost left with the question of which strategy they are enacting.

This ambiguity can perhaps be explained by the fact that, even though the VP understands the strategy as finished, about a third of the employees disagree, and, like for instance Bill, point out that some of the ambiguity that is present in the department's enactment, is caused by the unfinished character of the strategy. He explains:

I don't find that the current document is a done strategy. [...] The strategy [the interviewee makes quotation marks with his hands] we have now is only halfway there. 
Because what we have now is more like a nice introduction to what we do in this department - it is not a bouillon cube that in concentrated form tells you what our overall take on how to reach our goal is.

As such, he, and others, find the text to be unfinished, and too ambiguous to execute, therefore the actual practical strategy-work at the department will not be in alignment with the text. None of the employees seem to find this too problematic though, because, as earlier pointed out, they do not necessarily tie the enactment to the text.

In sum, for this concrete corporate communication department, the analysis depicts SCC as an activity in which clarity and ambiguity are co-present. First, in the writing of the strategy, there is, on a departmental level, shared meaning on the uselessness of the corporate mission, vision and values in formulating a corporate communication strategy, but, on an individual level, divergent and equivocal experiences of the purpose and authorship of the strategy. Second, in the reading of strategy, there is on a departmental level shared meaning on the objectives of the strategy, but, on an individual level, divergent and equivocal perceptions of what change, if any, the objectives represent. And third, in the enactment of the strategy, there is, on a departmental level, shared meaning on the work practices of the department, how they are connected to, just not described in, the strategy text, and on an individual level divergent and equivocal understandings of the relevance and completeness of the strategy. In short, when writing the strategy, the department seems to agree on leaving the purpose and role of the text up for interpretation, which in turn is exploited by the members of the department in their reading of the strategy and as well as the enactment. When reading the strategy, the ambiguous role given to the text allows for the different members to individually decide on its impact, and, when enacting the strategy, collectively cope with its relatively minor role in orchestrating their day to day strategy-work.

\section{Conclusion and discussion}

Previous SCC research has focused predominantly on the importance of clarity, and hence focused on how to achieve this, and avoid ambiguity. The purpose of this article on the other hand is to contribute to the field by theoretically and empirically exploring the presence of ambiguity in SCC, not at the expense of clarity, but as a companion. Inspired by the work of Abdallah and Langley (2014), as well as the earlier mentioned strategy-as-practice and strategy discourse 
scholars, this article has, through a case study of a corporate communication department, aimed to portray this co-presence of clarity and ambiguity in the writing, reading and enactment of strategy.

What the analysis shows is that the department in all steps of strategizing - writing, reading, and enacting - operate with both central and peripheral (Regnér, 2003), or building and dwelling (Chia \& Rasche, 2015), forms of strategizing, that are mutually productive, despite at times being completely contradictory. That is, their strategy-work is marked by the productiveness of the simultaneous presence of, yet inconsistency between formal planned work, and informal emergent work. What the dominant SCC literature would regard a worst-case scenario, is here shown to be quite the opposite. By allowing the impact of the strategy on the work of the department to be ambiguous, the collective affords the individual different avenues for defining their role in implementing the strategy, without impeding the department's work, or threatening the concrete execution. In relation to writing the strategy, there is formal clarity on the general value of mission and vision, and informal clarity their ineptness when it comes to crafting a concrete strategy text; a shared, yet contradictory understanding that affords ambiguous personal interpretations and valuations of the contribution and commitment to the writing process. In relation to reading the strategy, there is formal clarity on the general strategic objectives, and informal clarity on the commonplaceness (and randomness) of these objectives; a shared, yet contradictory understanding that provides space for ambiguous individual interpretations of the analytical soundness, visionary appeal and completeness of the strategy. And finally, in relation to enacting the strategy, there is formal clarity on the necessity for official strategy-work settings, and informal clarity that such settings exist independently from a concrete strategy text; a shared, yet contradictory understanding which allows for ambiguous independent interpretations of how to utilize and assess concrete meeting formats and work arrangements. In sum, what the analysis reveals is a collectively internalized double structure of formal and informal strategizing that affords space for ambiguous, yet constructive everyday corporate communication strategy-work.

The unproblematic presence of equivocality in relation to the role of the strategy text could perhaps be explained by how strategy texts are not necessarily about concrete projects, but about ambitions and aspirations the management have for the future. As Shotter (1993) argues: “...our talk is not about something which already actually exists, but is about what might be, what could be the case, or what something should be like" (p. 153). As such, the employees might not find the incongruity between the text and their concrete work problematic, because they know that the strategy itself is not a reflection of what should be doing, but rather aspirations for what they could 
be doing. As such, in line Sillince et al. (2012), the study shows how the presence of ambiguity does not necessarily impede the department's operation, nor its ability to collectively identify the main objectives that should and/or are driving their work. This is not to say that the ambiguity present in the department does not create situations that might be problematic for the organization, rather that these problems do not seem to have any major impact on the organization's performance.

One example of a problematic situation is how the presence of ambiguity in general can produce a situation in which ownership and sense of responsibility towards the strategy is not felt. In the interviews, some of the employees voice this both in direct terms (saying it is not their strategy, but the VPs) and in more indirect ways by interchangeably calling it "our", "their", and "her" strategy. This can, over time, as also Abdallah and Langley (2014) point out, possibly be harmful for the department's work, and strategies for how to avoid this have been suggested (see e.g. Bednarek, Paroutis \& Sillince, 2017), but as several of the quotes above show, since the strategy text itself is not given too much importance, or even relevance for the concrete work of the employees, this harm might not materialize. Instead the strategy is seen as a necessary exercise the department does in order to placate others, as visible in for instance Catherine's rejection of the strategy text's measurement tools, whilst acknowledging that these measurements might be useful for someone other than her.

Beyond this, scholars have also pointed out how the presence of ambiguity might actually be positive for the organization. Mohr (1983) for instance, argues that there can be many advantages to cultivating inconsistency among goals, such as increased creativity and flexibility. An argument similar to that of the earlier mentioned Eisenberg (1984, p. 235), who stated that

[a]t the organizational level, strategic ambiguity facilitates change through shifting interpretations of organizational goals and central metaphors. At the interpersonal level, ambiguity facilitates change through the development of relationships among organizational members.

Hence, as shown in this research, not only should we recognize the presence of ambiguity in SCC, but we should also allow it to exist as it might produce outcomes and possibilities the strategy itself does not make possible (see e.g. Gioia and Chittipeddi, 1991; Tracy and Ashcraft, 2001). 


\section{Limitations and implications}

Although this study is exploratory and based on a concrete case organization, the findings correlate with studies in the neighbouring field of strategic management, pointing to their potential relevance for the analysis of other situations of SCC. There are, however, some limitations that should be explored. One important factor that might influence to which extent the co-presence observed here would also be present in other settings is the degree to which the management puts emphasis on the actual strategy text as being an important tool for the orchestration of the concrete work in the organization. In this particular case, this was not the situation, as the VP explicitly made clear that she valued execution over planning processes. This prioritisation of execution over planning, and by extension strategic action over strategy text, also became clear when this author requested access to earlier drafts of the final text, as well as documents used during the formulation process. Some of them had been deleted, the VP explained, others she deemed not relevant for the analysis. But in settings where the actual strategy text is seen as an important tool, there might be more clarity than ambiguity present, although those settings also might produce ambiguity in relation to the enactment of the written orchestration, as observed in this study. A second, and related, factor is the degree to which contradictions and vagueness is less tolerated or possible, either due to resources or style of management. The organization in which this study was conducted is private, large and with a fairly solid economy. In addition, the head of the department is a manager who, as noted above, values doing over planning. As such, there might be more room for inconsistency seeing that there is economic and organizational room to fail, than one would find in settings that do not share these characteristics.

But more than pointing to the possible limitations of this study's generalizability, these limitations point to the need for further research on the co-presence of clarity and ambiguity in SCC. First of all, there is need for more research on processes of writing, reading and enactment of SCC in settings different than what is the case with the present study. This could for instance be of corporate communication strategy work in public organizations, such as municipalities, where resources might be different, as well as the managerial lenience towards inconsistency. Similarly, it could be interesting to investigate SCC work in new organizations, as this might shed light on the possible differences between new and established corporate communication departments in regards how determining a strategy text is viewed. Secondly, there is also a need for further theory development in relation to how we not only analyse, but also practice ambiguity in SCC work. A need made even more urgent by the rapid and accelerating development and introduction of new 
communication technologies, which produce new strategic possibilities and challenges for the corporate communication of organizations (Plesner \& Gulbrandsen, 2015), both in terms of formulation and implementation. 


\section{References}

Abdallah, C., \& Langley, A. (2014). The Double Edge of Ambiguity in Strategic Planning. Journal of Management Studies, 51(2), 235-264.

Alvesson, M. (1996). Leadership studies: From procedure and abstraction to reflexivity and situation. The Leadership Quarterly, 7(4), 455-485.

Alvesson M \& Kärreman D (2000) Varieties of discourse: On the study of organizations through discourse analysis. Human Relations, 53(9), 1125-1149.

Argenti, P.A. (2007), Strategic Corporate Communication. New Delhi: Tata McGraw Hill.

Ashcraft, K.L., Kuhn, T.R. \& Cooren, F. (2009). Constitutional amendments: "Materializing” organizational communication. The Academy of Management Annals, 3(1), 1-64.

Balmer, J.M.T. \& Greyser, S.A. (Eds) (2003), Revealing the Corporation: Perspectives on Identity, Image, Reputation, Corporate Branding and Corporate-Level Marketing, London, UK: Routledge.

Bednarek, R., Paroutis, S., \& Sillince, J. (2017). Transcendence through rhetorical practices: Responding to paradox in the science sector. Organization Studies, 38(1), 77-101.

Berkelaar, B.L. \& Buzzanell, P.M. (2015). Bait and switch or double-edged sword? The (sometimes) failed promises of calling. Human Relations, 68(1), 157-178.

Chia, R., \& Rasche, A. (2015). Building and dwelling world-views. Two alternatives for researching strategy as practice. In D. Golsorkhi, D. Seidl, L. Rouleau, \& E. Vaara (eds.), Cambridge handbook of strategy as practice (2nd ed, pp. 44-57). Cambridge, UK: Cambridge University Press.

Christensen, L.T., \& Cornelissen, J.P. (2011). Bridging corporate and organizational communication: Review, development and a look to the future. Management Communication Quarterly, 25 (3), 383-414

Christensen, L.T., Morsing, M. \& Cheney, G. (2008). Corporate Communications. Convention, Complexity, and Critique. London, UK: Sage.

Christensen, L.T., Morsing, M. \& Thyssen, O., (2015). The polyphony of values and the value of polyphony. Journal for Communication Studies, 8(1), 9-25. 
Cohen, M D., March, J. G. \& Olsen, J. P. (1972). A Garbage Can Model of Organizational Choice. Administrative Science Quarterly, 17(1), 1-25.

Cornelissen, J. (2000). Corporate image: an audience centered model, Corporate Communications: An International Journal, 5(2), 119-125.

Davenport, S. \& Leitch, S. (2005). Circuits of power in practice: strategic ambiguity as delegation of authority. Organization Studies, 26, 1603-23.

de Certeau, M. (1988). The Practice of Everyday Life. Berkeley, CA: University of California Press.

Denis, J. L., Dompierre, G., Langley, A., \& Rouleau, L. (2011). Escalating indecision: Between reification and strategic ambiguity. Organization Science, 22(1), 225-244.

Denis, J. L., Langley, A. \& Lozeau, D. (1991). Formal strategy in public hospitals. Long Range Planning, 24, 71-82.

Denzin, N. K., \& Lincoln, Y. S. (2000). Handbook of qualitative research. Thousand Oaks, CA: Sage.

Eisenberg, E.M. (1984). Ambiguity as strategy in organizational communication. Communication Monographs, 51(3), 227-242.

Eisenberg, E. M. (2006). Strategic Ambiguities: Essays on Communication, Organization, and Identity. Thousand Oaks, CA: Sage.

Emirbayer, M. (1997). Manifesto for a relational sociology. American Journal of Sociology 103(2), 281-317.

Fairhurst, G. \& Putnam, L. (2004). Organizations as discursive constructions. Communication Theory, 14(1), 5-26.

Gioia, D. A. \& Chittipeddi, K. (1991). Sensemaking and sensegiving in strategic change initiation. Strategic Management Journal, 12(6), 433-48.

Gioia, D. A. \& Mehra, A. (1996). Book Review of Weick's Sensemaking in Organizations. Academy of Management Review, 21(4), 1226-1240.

Goodman, M. B. (2006), Corporate communication practice and pedagogy at the dawn of the new millennium, Corporate Communications: An International Journal, 11(3), 196-213.

Grant, D., Keenoy, T. \& Oswick, C. (1998). Discourse and Organization. London, UK: Sage. 
Grunig, J. E. (2009). Paradigms of global public relations in an age of digitalisation. PRism, 6(2), 1 19.

Gulbrandsen, I. T., \& Just, S. N. (2016a). In the wake of new media: Connecting the who with the how of strategizing communication. International Journal of Strategic Communication, 10(4), 223-237.

Gulbrandsen, I. T., \& Just, S. N. (2016b). Strategizing Communication: Theory and Practice. Frederiksberg: Samfundslitteratur.

Hallahan, K., Holtzhausen, D., van Ruler, B., Verčič, D., \& Sriramesh, K. (2007). Defining Strategic Communication. International Journal of Strategic Communication, 1(1), 3-35.

Hazen, M. A. (1993). Towards polyphonic organization. Journal of Organizational Change Management, 6(5), 15-26.

Heracleous, L. (2006). Discourse, Interpretation, Organization. Cambridge, UK: Cambridge University Press.

Humphreys, M. \& Brown, A.D. (2002). Narratives of organizational identity and identification: A case study of hegemony and resistance. Organization Studies, 23(3), 421-447.

Jackson, P. (1987). Corporate Communication for Managers. London, UK: Pitman.

Jarzabkowski, P. (2004) Strategy as Practice: Recursiveness, Adaptation, and Practices-in-Use, Organization Studies, 25(4), 529-60.

Jarzabkowski, P., Balogun, J. \& Seidl, D. (2007) Strategizing: The Challenges of a Practice Perspective. Human Relations, 60(1), 5-27.

Jarzabkowski, P. \& Fenton, E. (2006). Strategizing and organizing in pluralistic contexts. Long Range Planning, 39(6), 631-48.

Jarzabkowski, P., Sillince, J. A. A. \& Shaw, D. (2010). Strategic ambiguity as a rhetorical resource for enabling multiple interests. Human Relations, 63(2), 219-48.

Jarzabkowski, P. \& Spee, A. P. (2009). Strategy-as-Practice: A Review and Future Directions for the Field. International Journal of Management Reviews, 11(1), 69-95.

Johnson, G., Langley, A., Melin, L. \& Whittington, R. (2007) Strategy as Practice - Research Directions and Resources. New York, US: Cambridge University Press 
Kaplan, S. (2007). Strategy as practice: an activity-based approach, by Paula Jarzabkowski. London: Sage, 2005 (Book Reviews). Academy of Management Review, 32(2), 986-990.

King, C. L. (2009). Emergent Communication Strategies. International Journal of Strategic Communication, 4(1), 19-38.

Lindblom, C. E. (1959). The science of 'muddling through'. Public Administration Review, 19, 7988.

Mantere, S., \& Vaara, E. (2008). On the problem of participation in strategy: A critical discursive perspective. Organization Science, 19(2), 341-358.

Mazzei, A. (2014). A multidisciplinary approach for a new understanding of corporate communication. Corporate Communications: An International Journal, 19(2), 216-230.

Mintzberg, H. (1994). The Rise and Fall of Strategic Planning. New York, NY: The Free Press.

Mohr, L. B. (1983). The implications of effectiveness theory for managerial practice in the public sector. In K. S. Cameron \& D. A. Whetten (eds.), Organizational effectiveness (pp. 225239). New York, NY: Academic Press.

Ormino, M. (2007), Managing Corporate Brands: A New Approach to Corporate Communication. Weisbaden: Gabler Edition Wissenschaft.

Plesner, U., \& Gulbrandsen, I. T. (2015). Strategy and new media: A research agenda. Strategic Organization, 13(2), 153-162.

Regnér, P. (2003). Strategy creation in the periphery: Inductive versus deductive strategy making. Journal of Management Studies, 40(1), 57-82.

Sajasalo, P., Auvinen, T., Takala, T., Järvenpää, M., \& Sintonen, T. (2016). Strategy implementation as fantasising-becoming the leading bank. Accounting and Business Research, 46(3), 303-325.

Seawright, J., \& Gerring, J. (2008). Case selection techniques in case study research a menu of qualitative and quantitative options. Political Research Quarterly, 61(2), 294-308.

Seiffert, J., Bentele, G., \& Mende, L. (2011). An explorative study on discrepancies in communication and action of German companies. Journal of Communication Management, 15(4), 349-367. 
Shotter, J. (1993). Conversational realities: Constructing life through language. London, UK: Sage.

Sillince, J., Jarzabkowski, P., \& Shaw, D. (2012). Shaping strategic action through the rhetorical construction and exploitation of ambiguity. Organization Science, 23(3), 630-650.

Silverman D. (2001). Interpreting Qualitative Data. Methods for Analysing Talk, Text and Interaction. London, UK: Sage.

Sinha, M. \& Bhatia, P. (2016). Strategic corporate communication and impact in Indian service sector. Corporate Communications: An International Journal, 21(1), 120-140.

Stake, R. E. (2010). Qualitative research: Studying how things work. New York, NY: Guilford Press.

Steyn, B. (2004). From strategy to corporate communication strategy: A conceptualisation. Journal of Communication Management, 8(2), 168-183.

Streb, C. (2010). Exploratory case study. In A. J. MillsG. Durepos \& E. Wiebe (eds.), Encyclopedia of case study research (pp. 373-374). Thousand Oaks, CA: Sage.

Tracy, K., \& Ashcraft, C. (2001). Crafting policies about controversial values: How wording disputes manage a group dilemma. Journal of Applied Communication Research, 29(4), 297-316.

Vaara, E., Sorsa, V., \& Pälli, P. (2010). On the force potential of strategy texts: a critical discourse analysis of a strategic plan and its power effects in a city organization. Organization, 17(6), 685-702.

Vaara, E. \& Whittington, R. (2012). Strategy-as-Practice: Taking Social Practices Seriously. Academy of Management Annals, 6(1), 285-336.

van Riel, C. B. M. (1995). Principles of Corporate Communication. London, UK: Prentice Hall.

van Riel, C. B. M. (2003). Defining corporate communication. In Bronn, P.S. \& Wiig, R. (Eds), Corporate Communication: A Strategic Approach to Building Reputation (pp. 21-40), Oslo: Gyldendal.

Van Riel, C. B. M. \& Fombrun, C. (2007). Essentials of Corporate Communications, New York, NY: Routledge.

Weick, K. E. (1979). The Social Psychology of Organizing. New York, NY: McGraw Hill. 
Whittington, R. (2006) Completing the Practice Turn in Strategy Research, Organization Studies $27(5), 613-34$.

Whittle, A. \& Mueller, F. (2010). Strategy, enrolment and accounting: the politics of strategic ideas. Accounting, Auditing \& Accountability Journal, 23(5), 626-646.

Yin, R. K. (2003). Case study research. London, UK: Sage. 